\title{
Social values influence the adequacy conditions of scientific theories: beyond inductive risk
}

\author{
Ingo Brigandt ${ }^{*}$
}

Department of Philosophy, University of Alberta, Edmonton, Canada

The 'death of evidence' issue in Canada raises the specter of politicized science, and thus the question of what role social values may have in science and how this meshes with objectivity and evidence. I first criticize philosophical accounts that have to separate different steps of research to restrict the influence of social and other non-epistemic values. A prominent account that social values may play a role even in the context of theory acceptance is the argument from inductive risk. It maintains that the more severe the social consequences of erroneously accepting a theory would be, the more evidence is needed before the theory may be accepted. However, an implication of this position is that increasing evidence makes the impact of social values converge to zero; and I argue for a stronger role for social values. On this position, social values (together with epistemic values and other empirical considerations) may determine a theory's conditions of adequacy, which among other things can include considerations about what makes a scientific account unbiased and complete. I illustrate this based on recent theories of human evolution and the social behaviour of non-human primates, where some of the social values implicated are feminist values. While many philosophical accounts (both arguments from inductive risk and from underdetermination) conceptualize the relevance of social values in terms of making inferences from evidence, I argue for the need for a broader philosophical framework, which is also motivated by issues pertaining to scientific explanation.

Keywords: epistemic values; social values; feminist values; androcentrism; inductive risk; theory acceptance; adequacy conditions; explanation

\footnotetext{
*Email: brigandt@ualberta.ca
} 


\section{1. 'Death of evidence' and the specter of politicized science}

Politicized science can be the subverting of sound science by outside influences as well as by political commitments of scientists. In recent decades, the US government under George W. Bush was more widely known for undermining science to further a pro-industry, anti-consumer protection, and anti-environment agenda (Mooney 2005). But also in Canada, Stephen Harper’s conservative government currently selectively underfunds scientific areas that would provide results not conducive to its political-economic agenda, and prohibits scientists working for government research agencies to speak to the press without political approval (Harris 2014; Rollmann 2014; Turner 2013). In 2008, the Canadian government decided to close the position of the non-partisan national science advisor, which had been created four years earlier (Hoag 2008); and it became known that Environment Canada ordered its scientists to refer all media inquiries to the government's communication officers, who would provide approved lines for the media (Ottawa Citizen 2008). Similar incidents followed, which the media described as the muzzling or gagging of government scientists (Reardon 2011; Saunders 2009). Examples are Environment Canada prohibiting its researcher David Tarasick to give interviews about his ozone layer research published in Nature, and the Privy Council Office barring Fisheries and Oceans Canada scientist Kristina Miller from talking about her findings on the decline of sockeye salmon that had appeared in Science (The Canadian Press 2012). In early 2012, the Canadian government announced the decision to close down the world-renowned Experimental Lakes Area freshwater research station and the unique Polar Environment Atmospheric Research Laboratory. ${ }^{1}$ This is to be seen against the background of the Harper government's reservations to climate change science findings and climate change mitigation efforts, having rescinded Canada's Kyoto protocol commitments and investing in a fossil-fuel based economy, including the Alberta tar sands (which are worse than other fuel-producing technologies in terms of 
greenhouse gas emission and its environmental impact on the extraction site and during pipeline transport incidents; see also Goldenberg 2013b).

Combined with severe cuts to other government research agencies and the budgets of granting agencies that fund basic research conducted at Canadian universities, this led to the highly unusual event of a political rally held by scientists. On July 9, 2012, at a mock funeral on Ottawa’s Parliament Hill, scientists mourned the 'death of evidence' (Davison 2012; Pedwell 2012). Canada’s government continues to be subject to media criticism (Galloway 2013b; Globe and Mail 2013; Goldenberg 2013a; Linnitt 2013). This includes the charge of continuing to muzzle government scientists (CBC News 2012, 2015; Galloway 2013a; Gatehouse 2013; Globe and Mail 2014; Klinkenborg 2013; for a detailed overview see Turner 2013), which has prompted the Federal Information Commissioner to begin an investigation into the complaints about the government (Semeniuk 2015). Some of the critical commentaries also come from science journals (Nature 2008, 2012, 2013; O'Hara 2010) and philosophers of science (Douglas 2013a; Gatehouse 2013). ${ }^{2}$

The ‘death of evidence' issue in Canada highlights the damaging effect of political interference with and undermining of science. At the same time, while upholding sound science and evidence as something that society should subscribe to regardless of one's individual beliefs and values, the scientists' protest is also a political stance against the Harper government's political agenda, and the objection to this selective underfunding stems from their valuing of the environment and public health. ${ }^{3}$ This likewise raises the spectre of politicized science, or at least the question of what role scientists’ values may play in science. Indeed, while clearly acknowledging some need for values, Stathis Psillos (2015) wonders which social values have an improper influence or even infringe on evidence. This framing of evidence and values is rejected by Helena Likwornik (2015) on the grounds that both are necessarily entwined, and Maya 
Goldenberg (2015) argues that also values are based on and in this sense embody empirical evidence. In what follows, I will contribute to general philosophical discussions on science and values. While many prior accounts make some room for social values while showing how this avoids politicized science, I shall argue for a stronger role for social values. ${ }^{4}$

Upon reviewing some previous accounts of the role of values, in Section 3 I criticize the strategy of allocating different values to different steps of research, which has also been used by many sympathetic to social values in an attempt to provide a clear-cut distinction between the licit use of a value (in a certain research step) and illicit politicized science. The most convincing position for values in the context of theory acceptance has been the idea that social values can influence the evidential threshold. This argument from inductive risk maintains that we should demand more evidence (before hypothesis acceptance) if accepting an actually false hypothesis would have severe social and other practical consequences (e.g., Douglas 2009). However, such accounts have the consequence that when evidence increases (and thus any given evidential threshold is met) the impact of social values converges to zero. Using the case of past accounts of human evolution and primate social behaviour — which were both empirically flawed and sexist—in Section 4 I suggest that not only epistemic considerations, but also social and environmental values may determine a scientific theory's conditions of adequacy. Various considerations can be used by scientists to judge the adequacy of a theory, depending on the particular case, but in our context this includes what it means for the theory to be unbiased and complete. The role of conditions of adequacy is not diminished at all by evidence accumulating, so that my central aim is to argue for a stronger role for social values in the context of theory acceptance. This position is clarified and defended in Section 5, where I point out that my account cannot be captured by prior approaches that conceptualize theory acceptance solely in terms of making inferences from evidence, sketching a broader framework by creating 
connections to philosophical discussions of scientific explanation (which motivate and support my perspective, even though they did not engage with social values). The concluding section returns to the worry about politicized science.

\section{Inductive risk and other prior accounts of the role of values}

Philosophical discussions of the relation between science and values have gained prominence during the last two decades (Barker and Kitcher 2013; Douglas 2009; Kincaid, Dupré, and Wylie 2007; Kitcher 2001; Lacey 1999; Longino 1990; Machamer and Wolters 2004). Furthermore, viewing science as including social values and being answerable to society has recently been complemented by a new vision of philosophy's aims, in terms of a socially relevant and socially engaged philosophy of science (Plaisance and Fehr 2010; see also Kourany 2010, ch. 5). ${ }^{5}$ There are still some who uphold the ideal of 'value-free' science, but even a restrictive position does not deny that values can play a legitimate role in science. Rather, the strategy is first to distinguish between epistemic and non-epistemic values (McMullin 1983; Dorato 2004; Douglas 2000; Rooney 1992) — the terminology of cognitive as opposed to non-cognitive values is likewise used (Laudan 1984; Lacey 2004). ${ }^{6}$ While ethical, social, and environmental values are non-epistemic, epistemic values include a theory's internal consistency, its fit with evidence, its consistency with other theories, its predictive accuracy, its generality and unifying power, and its simplicity. It is uncontroversial that many, if not all of these epistemic values are rightly used by scientists. Second, different steps of scientific research are distinguished, for instance research project choice, hypothesis acceptance, and knowledge application (Douglas 2000). Everyone has to acknowledge that even non-epistemic values may be used in the choice of a research project and the technological application of knowledge, for example, scientists may study the effects of climate change on biodiversity because of an environmentalist agenda. Consequently, those who 
maintain that science ought to be 'value-free' distinguish different research steps so as to focus on the core step of science-accepting hypotheses by evidence—and maintain that in this context of theory acceptance, only epistemic values may be used.

But even excluding social values from theory acceptance would not undermine the philosophical need to study such values, given that other aspects of scientific research raise epistemological questions and have social impacts. The 'death of evidence' issue in Canada vividly highlights the societal effect of choosing certain lines of research (or not being able to do so due to selective underfunding), and of communicating and applying scientific knowledge (or being prevented from communicating results). Against the idea of a global aim of science, Philip Kitcher (2001, ch. 6) has argued that scientific aims are particular aims arising locally in a discipline, where their scientific significance often combines intellectual and practical, application related considerations. Going beyond this, Janet Kourany (2010, ch. 5) stresses the importance of critically_-based on social values—evaluating the research problems scientists work on and the application of their results, and argues that philosophers of science should devote more of their work to these research steps. How even the choice of research projects can be philosophically scrutinized involving a combination epistemic and ethical-social considerations can be illustrated by Inmaculada de Melo-Martín and Kristen Intemann’s (2011) investigation of the development of HPV vaccines. Current virus-like-particle vaccines are expensive to produce, have to be stored using refrigeration, and are effective only when three doses are administered over a 6 month period. As result, the available vaccines will not benefit people in developing countries, who are most in need of HPV prevention. Yet de Melo-Martín and Intemann argue that at least in the past researchers did have the option of exploring other feasible types of HPV vaccines (naked DNA and live bacterial vectors), which are much more likely to be of benefit in developing countries. This yields guidelines for how more socially 
responsible science would look like, which are concrete given the epistemic-empirical considerations used.

In any case, there have been two basic arguments that social and other non-epistemic values matter even in the context of theory acceptance (Brown 2013; Rottschaefer 2003). One is the argument from underdetermination. Sometimes it is phrased in terms of auxiliary hypotheses (Anderson 2004; Campbell 1994, 1998; Intemann 2001). Starting with the assertion that a theory cannot be tested in isolation and has testable consequences only once combined with an auxiliary hypothesis, the observation is that there are actual cases where the auxiliary hypothesis used embodies social values or that scientists' preference for using this auxiliary hypothesis was based in part on social values. Moreover, different auxiliary hypotheses could be used (resulting in a different outcome for the theory to be tested), and since empirical considerations alone cannot settle which auxiliary hypothesis is to be chosen, there is nothing to rationally prevent one from choosing a theory because it aligns with one's social values. The latter idea is often directly phrased in terms of underdetermination (Intemann 2005; Longino 1990, 2002; Psillos 2015). The argument is that a theory is always underdetermined by evidence alone, so that additional considerations are needed to fill the gap between evidence and theory. Values, including social values, are not only an unavoidable, but also fruitful way to achieve theory choice. In the remainder of my discussion, I focus on the other type of argument for social values in the context of theory acceptance, given that it is often seen to be the more convincing one.

The argument from inductive risk stems from Richard Rudner’s (1953) seminal account, according to which ethical and other non-epistemic values may influence the amount of evidence that is deemed to be sufficient for accepting a hypothesis. Using Hempel’s (1965) terminology, this approach is nowadays typically discussed under the label of inductive risk (Douglas 2000; Elliott 2011b; Steel 2010, 2013), given that evidential support for an empirical theory is always 
inductive, and given that accepting even a very well-supported theory is a risk, as it could still turn out to be false. But accepting and acting on a hypothesis that is actually false may have bad social and other practical consequences, for instance, approving a new drug on the erroneous assumption that it has no serious side-effects. Thus, the more severe the consequences of endorsing a false hypothesis would be—-by the light of social and other ethical values—-the more evidence is needed before this hypothesis can be accepted. In line with this, Kitcher (1985) emphasized that the standards for sociobiological explanations claiming human social behaviours, e.g., racism or social hierarchies, to be evolutionary adaptations ought to be at least as high as the evidential standards used in evolutionary accounts of animal behaviour (and then offered an empirical argument that often the stark opposite was the case).

Heather Douglas (2009) has prominently elaborated this approach by distinguishing between a direct and an indirect role for values. A hypothesis must not be accepted because it fits one's social agenda—which would be a direct role for social values—it is to be accepted because it is supported by evidence. But social and other non-epistemic values may be invoked to require more evidence, or to tolerate less uncertainty, when accepting a theory. ${ }^{7}$ In this sense, social and other non-epistemic values play an indirect role, by modulating the evidential threshold, but not functioning as evidence. ${ }^{8}$ Thus, Douglas's direct-indirect distinction is to lay out how non-epistemic values can play a legitimate role in theory acceptance, while articulating a safeguard against a politicized science, which is not strictly committed to scientific objectivity but would endorse theories merely because they align with a political agenda:

In the cases of politicized science, the norm against a direct role for values in the decisions about empirical claims is violated. ... The conceptual structure I have described in this chapter thus allows for a clear distinction between value-laden and politicized science. (Douglas 2009, 113) 
Moreover, the direct-indirect distinction goes beyond the context of theory of acceptance-on which most other accounts of inductive risk focus_-given that according to Douglas, social and other non-epistemic values may indeed play a direct role in various other aspects of scientific research, e.g., research problem choice.

While this basic framework makes sense, let me question some of the details. Unlike many others, Douglas does not use ‘epistemic value’ and 'cognitive value’ as synonymous. Inspired by Laudan (2004), she views only internal consistency and predictive competency (i.e., fit with evidence) as epistemic, whereas she classifies other empirical values (such as broad scope, fruitfulness and simplicity) as cognitive values, on the grounds that such features of a theory are not indicative of its truth—-the hallmark of the epistemic. In fact, Douglas does not take the epistemic criteria of internal consistency and predictive competency to be genuine values, ${ }^{9}$ and sharply separates them from cognitive, ethical and social values. Epistemic criteria can always be used in a direct role, whereas values — be they cognitive or social—may only have an indirect role in the context of theory acceptance. Thus, not only is the distinction between direct and indirect roles a novel idea of Douglas's, for her it is the only important difference, unlike the traditional distinction between cognitive and social values:

The crucial normative boundary is to be found not among the kinds of values scientists should or should not consider (as the traditional value-free ideal holds), but among the particular roles for values in the reasoning process. (Douglas 2009, 88; emphasis added)

A minor issue is that Douglas strictly separates internal consistency and external consistency (see also Douglas 2013b), where unlike a theory’s internal consistency, the 'consistency of a theory with other areas of science is [merely] a cognitive value' (Douglas 2009, 93). Apart from the fact that others may argue that using the criterion of 'being (in)consist with other theories' is epistemically legitimate (when the other theories are likely to be true), Douglas's account is 
incoherent, given that ' $\mathrm{T}$ being consistent with theory $\mathrm{X}$ ' is simply ' $\mathrm{T} \& \mathrm{X}$ being internally consistent.' Of course there are pragmatic reasons for why a body of assumptions $\mathrm{T}$ is individuated so as to distinguish it from $\mathrm{X}$, but this cannot yield the categorical distinction that Douglas postulates between the epistemic criterion of 'being internally consistent' and the (cognitive) value of 'being consistent with other theories,' where only the former may have a direct role in theory acceptance.

More problematic is that Douglas (2009) takes the distinction between a direct and an indirect role to hold for all values and to apply across contexts, ${ }^{10}$ without actually explicating the distinction for all these situations. First, consider an aspect of science apart from theory acceptance, say choosing a research project. In this context it is clear what it is to use a social or environmental value in a direct role (e.g., studying climate change because of one’s environmentalist values). But what could it possibly mean to use the same value in a different, indirect role when choosing a research project, or in any situation outside of theory acceptance? Second, the context of theory acceptance is where Douglas's distinction promises to have most traction, given that epistemic criteria may play a direct role, while cognitive, ethical, and social values may play an indirect role only. For social and environmental values, there is indeed a distinction: endorsing a hypothesis because acting on it would have consequences that are positive in light of the value (direct role), as opposed to increasing the evidential threshold to the extent to which acting on the actually false hypothesis would have consequences that are negative in light of the value (indirect role). Yet Douglas includes cognitive values, such as a theory's simplicity. She views accepting a hypothesis because it is simple (and rejecting a hypothesis because it is not simple) as illicit, and classifies this as using the value in a direct role (102). Yet what could it possibly mean to use a cognitive value like simplicity in a different, indirect role when assessing theories? The indirect role is the only way a cognitive value such as 
simplicity may be used according to Douglas, but she does not explain what this would be, and why this is the same indirect role as for social values. It cannot have anything to do with simplicity increasing the evidential threshold, as in the case of social values. ${ }^{11}$

It appears that Douglas has not offered a convincing articulation of her separation between epistemic criteria and values (which include cognitive values), and her distinction between a direct and an indirect role. This is a drawback insofar as the distinction promised a clear boundary between properly value-using science (committed to objectivity and evidence) and illicit politicized science. Be it as it may, I now move on to more interesting limitations of her framework, given that they also hold for many other accounts of the relation between science and values.

\section{The limited relevance of segregating different research steps}

Arguments from inductive risk as such pertain to theory acceptance; and in the following sections I will focus on the context of theory acceptance as well. But I start out with broader considerations that have implications for different accounts of the role of values in science (and which will turn out to be relevant for my particular account of theory acceptance, as Section 5 will explain). Not only those who still maintain that non-epistemic values should not impact theory acceptance in any way (while acknowledging that values may be used in other aspects of research) separate theory acceptance from other steps of scientific research. Even some proponents of inductive risk arguments, to the extent to which in the context of theory acceptance they restrict the role of social values (to the setting of the evidential threshold), have to distinguish different steps of research. Heather Douglas’s (2009) position is that non-epistemic values may play a direct role at some steps of research (e.g., research project selection and knowledge application), whereas the situation is different 'in the heart of doing science-during 
the characterization of data, the interpretation of evidence, and the acceptance of theories' (102), given that 'a direct role for values at this point in the scientific process is unacceptable, but an indirect role is legitimate' (96, emphasis added).

While there is nothing wrong with distinguishing different aspects or steps of research, I argue that there are limits to the philosophical strategy of segregating different research steps with the aim of being able to adjudicate whether a particular value was licitly (or illicitly) used by looking at this one step. One basic reason is that the actual outcome of research, e.g., a journal article endorsing a hypothesis, requires a sequence of several steps, so that a critical evaluation of this research—be it on epistemic or on social grounds—sometimes cannot assign blame to an individual research step regardless of the outcome it only yields in combination with other steps. A good example is the well-known fact that drug trials sponsored by the companies producing the drug are more likely to find it effective and without serious side-effects than independent studies (Lundh et al. 2012). Something wrong is going on here, but it is usually not the case that the authors would falsify data or use shoddy statistical methods—-the papers pass rigorous peerreview precisely because they follow standard epistemic procedures. The explanation for the bias is that industry-sponsored trials know to 'ask the right questions' (Smith 2005), e.g., having the trial drug run against too low a dose of a competitor drug (making the trial drug seem more effective) or against too high a dose of a competitor drug (making the trial drug's side-effects appear relatively minor).

This asking of particular questions to get a more favourable outcome does indeed belong to the step of research question selection or the step of experimental methodology selection (which of these steps, or both?). But there is nothing intrinsically wrong about asking such a question, e.g., comparing the drug against a particular competitor drug with a certain dosage. What is first and foremost problematic is the impact that the published results would have, where 
the results follow from the question pursued in combination with an experimental methodology and statistical means of data evaluation —-the latter being the 'hypothesis acceptance based on evidence' step. Likewise, using a statistical inference method is not licit in every case, but whether it is legitimate depends on the research context, where the relevant context may contain other 'steps' of research. Thus, even if one can assign (epistemic or social) blame to a particular aspect of research, e.g., the asking of a certain question, this verdict can often be made only because of how this step connects up with other research steps. Conversely, in general one cannot give a free pass to a value's use, as long as this use pertains to a specific step of research. Janet Kourany’s (2010) call for the ideal of a socially responsible science assumes that considerations involving social values hold for every aspect of research. She does not offer an argument for this, given that she does not explicitly address the rival position that social values may play a direct role at some research steps, but not in the acceptance of theories. But one of her examples illustrating socially responsible science is highly instructive. The studies by psychologist Carolyn West (2002) on domestic violence aim at improving the condition of black woman in the US. Despite uncovering some similarities among black and white communities, this research faces the challenge of exhibiting domestic problems encountered specifically by black women without perpetuating the stereotype that black men are inherently more violent. The pursuit of this dual social aim 'affects not only research questions but also ... such aspects of research as concepts (e.g., the concept of "partner violence” itself); measurement scales and techniques; methods of subject selection; strategies of data collection, analysis, and interpretation; and even methods of publishing and disseminating results' (Kourany 2010, 72). In particular, it requires broadening the definition of 'partner violence' to include emotional and sexual in addition to physical abuse and to change the measuring of sexual violence by taking its context into account. 
This suggests the second reason for why one cannot base one's account of the role of values on a separate treatment of steps of research. Scientists' use of particular definitions, categories, and concepts impacts all aspects of research. And sometimes a category (e.g., 'partner violence') embodies value-judgments, or more precisely, its scientific use leads to an effect that is more problematic than an alternative definition would have. ${ }^{12}$ An example that goes beyond social science is climate change research (Schienke et al. 2011). Climate management models may use the concept of 'utility' as a measure of global wealth, which is to be maximized by an appropriate climate change mitigation strategy. But if utility is defined in terms of average global wealth, the model ignores any global inequities, even though climate change will have particularly severe impacts on some human populations and mitigation efforts may enhance existing inequities. Conversions of floods, droughts, and other climate change induced events into units of monetary value likewise embody values. In summary, the formation of a proper scientific category, and a value-based criticism of a category used (regardless of whether more epistemic or more social considerations are involved), are to be done in the light of several research steps and their joint operation.

Some philosophical accounts segregate different steps of research and restrict the role of social values to certain steps, in an attempt to make room for values without compromising the objectivity of science. My considerations have questioned the success of this strategy. For instance, allowing values to be used in the choice of research questions may not prevent such values having a (problematic) impact on the acceptance of theories, given the wide-reaching ramifications of scientific categories (which may be value-laden), or given the way in which asking a certain research question may bias what the evidence-based outcome will be (as in the case of industry-sponsored drug trials). Douglas actually recognizes the latter issue: 
Not all direct roles for values in these early stages of science should be acceptable, however. One cannot use values to direct the selection of a problem and a formulation of a methodology that in combination predetermines (or substantially restricts) the outcome of a study. (Douglas 2009, 100)

However, this admission qualifies her basic idea that values may be used in a direct role in the context of research problem choice-without offering an account of the conditions in which the direct role is illicit. Given that one would have to look at a context larger than research problem choice, such an account would go beyond Douglas's philosophical distinction between direct and indirect roles. ${ }^{13}$ That said, I do not recommend a solution in terms of restricting the general influence of values even further. In contrast to any philosophical account segregating steps of research, there may be no general articulation of the role of social values - at least one which considers research steps in isolation—ensuring a clear boundary that prevents the use of values to lead to an improperly commercialized or politicized science. But this situation is unlikely to be specific to social values, in that sometimes the problematic use of an epistemic value or method can only be criticized based on a consideration of the overall process of research.

\section{Toward a role for social values beyond setting the evidential threshold}

Arguments from inductive risk clearly demonstrate that social values matter even in the context of theory acceptance. However, unless one adds a further role for social values, one implication of inductive risk approaches is that the impact of social values converges to zero upon evidence accumulating. For on such accounts the role of social values is to influence the evidential threshold, and increasing evidence will meet any evidential threshold. As Heather Douglas puts it: 
the values do not compete with or supplant evidence, but rather determine the importance of the inductive gaps left by the evidence. More evidence usually makes the values less important in this indirect role, as uncertainty reduces. ... The indirect role ... can completely saturate science, without threat to the integrity of science. ... If we find new evidence, which reduces the uncertainties, the importance of the relevant value(s) diminishes. In this indirect role, more evidential reasons in support of a choice undercut the potency of the value consideration, as uncertainty is reduced. (Douglas 2009, 96-97)

This shows that Douglas fully endorses this diminishment of the role of social values, as it excludes a politicized science where values would function as evidence (Douglas 2009, 113 \& 122). However, my main aim in this paper is to argue for a stronger role for social and other non-epistemic values in the context of theory acceptance, a role that does not decrease with the accumulation of evidence. ${ }^{14}$ I do so by calling attention to a 1995 paper by Elizabeth Anderson, in which she proposed a 'cooperative model of the interaction of normative and evidential considerations in theory choice.' An insight of hers deserves to be quoted:

... not every set of true statements about a given phenomenon constitutes an acceptable theory of that phenomenon. Some sets offer a distorted, biased representation of the whole. This can make them unworthy representations of a phenomenon even if they contain no falsehoods. But what constitutes an adequate, unbiased representation of the whole is relative to our values, interests, and aims, some of which have moral and political import. (Anderson 1995, 37)

Anderson illustrated this by discussing the Nation of Islam's book The Secret Relationship between Blacks and Jews, which, even if all alleged facts were true, would still offer a biased (anti-Semitic) account of the role of Jews in $17^{\text {th }}$ century Atlantic slave trade. Here I point to the natural sciences to make a case for a strong role for social values, namely, recent accounts of human evolution and primate social behaviour. 
Past theoretical accounts of human evolution and archaeological field studies had an androcentric bias toward men’s innovations (Schiebinger 1999; Wylie and Hankinson Nelson 2007; Zihlman 1997). This was aggravated by some approaches trying to pinpoint a particular cognitive, behavioural, or technological innovation that was especially instrumental in making our ancestors modern humans. Dominant until the 1960s, the man-the-hunter account assumed that hunting furthered the development of bipedalism, an enlarged brain, and tool use. It featured hunting, especially big-game hunting, as an activity of men, which as a socially coordinated activity required new cognitive abilities. This overall vision was qualified by the addition of the woman-the-gatherer account, which saw women not just as passive in human evolution, but contributing to subsistence and the development of tools required for gathering. It was shown that for the majority of our ancestors most of the caloric intake did not come from big-game hunting, where women are likely to have provided more overall food by weight than men.

While initially the archeological record about even stereotypically female activities was largely ignored, sometimes rationalized by the assumption that women's activities are archeologically largely inaccessible due to their more perishable artefacts (unlike stone tools), nowadays the role of gender and the specific contributions of women has become an important dimension of investigation. Even the woman-the-gatherer account has come to be seen as stereotyping gender roles as well as being empirically inadequate. This has led to the reinterpretation of previous data. For instance, pestles and other tools had originally been interpreted as indicating female household activity in many cases of being found with a woman, yet as evidence of men manufacturing such tools when the same kind of tool was found with a man. Novel kinds of data has also been made possible by the new perspective, such as the search for traces of more perishable artefacts, or analyses of bone breakage patterns and stone tool wear 
patterns, which provide evidence of secondary processing (after hunting and butchering), and thus sophisticated tool use involving women.

A similar situation was to be found in accounts of non-human primate social behaviour (Hrdy 1981, 1986; Schiebinger 1999; Strum and Fedigan 1999, 2000). Early studies happened to devote more observational and theoretical attention to the activities of male primates. Individuals were categorizes as dominant males, peripheral males, and females / young, so to the extent that the social role of female primates was investigated, it often boiled down to reproduction and rearing offspring. Indeed, even if the scope of research is not overall social behaviour but more specifically sexual behaviour, female sexuality cannot be restricted to reproductive sex, as philosopher Elizabeth Lloyd (1993, 2005) has argued. She points to studies who run afoul of this by observing male-female sex only or more explicitly considering female behaviour as sexual only if it is reproductive, ${ }^{15}$ even though it is known that in many primate species females engage in sexual activities outside the estrus (and thus independently of reproduction) and in bonobos among others there are widespread female-female sexual interactions.

The observational focus of early primatology led to accounts that were similarly androcentric as past theories of human evolution, in that they entailed more active behaviours and a more influential social role for male primates, while females were initially seen as being noncompetitive and submissive, trading sex for food and protection. Observations and theoretical interpretations were also guided by the theory of sexual selection. Introduced by Darwin, sexual selection maintains that in animals it is the males that compete among each other (for access to females), while a female chooses a suitable male, which has led to the stereotype of the promiscuous male primate and the 'coy' female primate. This bias started to be remedied only when a larger proportion of female researchers entered primatology (Small 1984), who discovered female competition for reproductive success and female sexual assertiveness. Female 
promiscuity includes extra-pair mating that enhance the female's fitness while she maintains the support of her existing partner, or engaging in sex with multiple males who all contribute to caring for the offspring. The significance of female bonding and matrilineal networks has been discovered and come to be studied. It was likewise revealed that engaging in special social relationships with females can have a higher impact on a male's reproductive success than his rank in a male dominance hierarchy. In baboons, it is females who provide social stability to groups (while males move across groups), and older females who determine foraging routes. The theoretical framework of sociobiology to view each animal as choosing among several strategies depending on what currently is fitness enhancing has made it possible to view even seemingly passive female behaviour as discriminatorily exhibited in this context only and as an active, opportunistic choice. Furthered by novel theoretical perspectives, these various findings about different primate species led to the recognition that females' behaviour is richer, more diverse, and of more biological impact than previously assumed.

I have briefly reviewed theories from the recent history of archaeology and primatology that were empirically flawed and had sexist connotations. One point that these empirical cases show is that to arrive at an adequate scientific account, it is not sufficient to rely on an evidential basis no matter how true. (Recall Anderson's claim that there can be ‘unworthy representations of a phenomenon even if they contain no falsehoods.') In fact, when for instance only male primates happen to be studied, enlarging the amount of observations would lend better support to what is actually an inadequate, because gender-biased, theory of primate sociality. This is an issue obscured by accounts of inductive risk, which focus on reducing uncertainty by increasing the amount of evidence. ${ }^{16}$ Demanding that the observational base include all facts in the domain is not a satisfactory philosophical move, as a scientific model may legitimately abstract away from many individual details. Instead, in addition to conformity to some evidential basis, there 
are further conditions of adequacy that a scientific theory has to meet. Such conditions of adequacy can include standards of what it means for the theory to be unbiased and complete, and on my account, both epistemic and social values determine a theory's conditions of adequacy. This is not to deny that social values are also important for specifying what kind of evidence is to be gathered. But my approach is to move philosophical attention to the properties of theories, including what kind of theory is intended and what such a theory's conditions of adequacy are (which then ground what kind of evidence is needed). Conditions of adequacy are standards that always have to be met by a theory, so their role is not diminished when evidence accumulates or scientific uncertainty decreases. So if I am right that social values influence a theory's adequacy conditions, this yields indeed a stronger role for social values than recognized by inductive risk (and other) approaches. I will articulate my account in more detail and defend it, based on the above biological case, in the following section.

\section{Beyond the inference-from-evidence framework: a theory's purpose and adequacy conditions}

Many philosophical accounts of how social and other values matter for theory acceptance operate within what I call an inference-from-evidence framework, i.e., they focus on the relation between evidence and theory, typically proceeding from evidence so as to wonder whether it inferentially warrants theory acceptance. Consequently, how values matter is framed in terms of how values bear on the evidence-to-theory inference. This framework is obviously used by inductive risk approaches, which address evidential thresholds—what counts as a sufficient amount and strength of evidence-and invoke the concomitant notions of uncertainty and risk in inductive inference. But it also holds for underdetermination arguments for values, given that their starting point is that theory choice is underdetermined by evidence alone (Section 2), so that 
values have to bridge the gap between evidence and theory. I generally want to go beyond a philosophical framework that conceptualizes these issues exclusively in terms of making inferences from evidence, and motivate my broader picture as follows (also creating a connection to the issue of scientific explanation).

In the article on which I relied above, Anderson (1995) sets up her discussion by criticizing a 10-step argument for the idea that values cannot play a role in the justification of theories, which she broadly ascribes to Susan Haack (1993). (See also Haack 1996, which shows that Haack's concern is to prevent politicized science.) The first two steps are most relevant for my purposes, so I restate only them:

1. Significant truth is the sole aim of theoretical inquiry.

2. Whether a theory is justified depends only on features indicative of its truth, not its significance. (Anderson 1995, 33; emphasis added)

This aligns with an idea we have already encountered, the traditional tenet that while considerations of significance—including social relevance—may well be used when choosing research problems, in the context of theory acceptance only fit with evidence matters, but significance does not. But philosophical accounts of scientific explanation—and thus considerations independently of social values—already show premise 2 to be flawed. It is wellknown that not every true representation qualifies as an explanation (Craver 2007). A scientific representation may merely describe a phenomenon or capture correlations among features without explaining. More than truth and fit with observations is needed, to wit, an explanation has to reveal explanatorily relevant features, such as genuine causal relations. Many scientific theories are expected to offer explanations, so that pace Haack such theories are accepted only if the account meets considerations of (epistemic) significance, such as explanatory capacity. 
Explanatory accounts can be very complex. Alan Love (2008) uses the notion of a 'problem agenda' for a complex scientific problem that consists of many individual but related questions. He views a problem agenda as being tied to various (implicit) criteria of explanatory adequacy, which determine what conditions an adequate explanatory account has to meet. In the scientific case he considers, the explanation of the evolutionary origin of novelties (e.g., the jaw, originating in the transition from jawless vertebrates to jawed vertebrates), the criteria of explanatory adequacy entail that explanatory contributions are needed from genetics, cell, and developmental biology, from systematics and paleontology, and from ecology, so that a multidisciplinary account is required. Love argues that any adequate explanatory framework of the origin of novel traits must address not only structural but also functional aspects of traits, among other things (Brigandt and Love 2012; Love 2013a).

This biological case likewise shows that criteria of adequacy are far from straightforward (even when only epistemic-empirical issues are at stake). The considerations are much more complicated than the guideline of putting forward an explanation by adducing causes or mechanisms; in fact, there are serious biological disputes about the relevant criteria of explanatory adequacy in the case of evolutionary novelty. Some evolutionary developmental biologists favour explanations in terms of changes in gene regulatory networks, while others maintain that a broader framework is required, which addresses the developmental interaction of genetic and non-genetic features on several levels of organization. And some mainstream evolutionary biologists reject the aspirations of evolutionary developmental biology and claim that a traditional population genetic explanation is all that is needed (Love 2013b, 2013c; Love and Lugar 2013). Explanatory standards are often merely implicit assumptions, which may well be in need of scrutiny. For instance, Jason Robert (2004, ch. 1) grants the fruitfulness of the strategy in developmental biology of investigating the causal impact of genes, while holding 
other factors constant. However, he rightly insists that some biologists' implicit assumption that an adequate explanation of development can be given in terms of the activity of genes only may well be prompted, but cannot be justified by this experimental methodology—which does not even investigate the causal role of non-genetic factors (given that they are held constant). ${ }^{17}$

Now the connection to the topic of social values should become clear. Prior philosophical accounts surrounding scientific explanation (independently of any engagement with social values) have recognized that conformity with an evidential basis is not enough, but that many scientific theories have to fulfill standards of scientific significance, such as conditions of explanatory adequacy. Depending on the scientific purpose for which a particular theory is being developed and used, there are certain conditions of adequacy the theory has to meet, which apart from being explanatory (required of only some theories) can include conditions of what makes this theory unbiased, complete, and/or practically applicable. My account now maintains that $a$ theory's conditions of adequacy are determined not only by empirical considerations and epistemic values, but also by social, environmental, and other non-epistemic values, if the theory is intended to capture empirical features that matter by the light of the non-epistemic values, or if the theory's use has social or environmental implications.

In the case of a theory of human evolution or primate social behaviour, among other things the conditions of adequacy stipulate that to be complete, the theory include the social contributions of women (to the extent that they impact human evolution) or the social role of female primates_-both the social influence that aligns with men's / male primate's and that is distinctive to women / female primates. Some may grant that past theories in these domains were indeed inadequate, while arguing that social values are not implicated given that the theories were inadequate with respect to purely epistemic considerations, e.g., the capturing of all explanatorily relevant social activities. One problem with this construal is that it does not quite 
align with the considerations of some of the scientists involved. While several of the for the most part female biologists who criticized and rectified past accounts denied to have employed an explicit feminist agenda and in some cases may not even have identified using the label 'feminist,' it is clear that at the very least an implicit gender-sensitivity has played a role in their theoretical reflections (Fedigan 1997; Kourany 2010; Schiebinger 1999; Strum and Fedigan 1999). The same holds for past work in archaeology (Conkey and Gero 1997; Conkey and Spector 1984; Hanen and Kelley 1992; Wylie and Hankinson Nelson 2007).

But regardless of what values motivated (some) scientists in the past, these scientific accounts can and should be scrutinized also based on such social values as gender equity. I indeed claim that the very value of gender equity is relevant. For my account distinguishes between conditions of adequacy, which are scientific standards to be met by a theory (e.g., (include the social role of females'), and the values and other considerations that guide the formulation of adequacy conditions. In this particular scientific case, the value of gender equity does not entail that the same social roles or sex-related behaviours are to be ascribed to males and females, but that the social contributions of females (be they similar or different from males') are to be captured by the theory.

One possible reason for this is that gender-biased and empirically flawed accounts of human evolution—and even of non-human primate sociality—can make current human gender stereotypes or inequities seem to reflect a general natural reality. This would justify adequacy conditions based on the social consequences that the promotion of an inadequate theory would have, analogous to how inductive risk accounts appeal to the consequences of endorsing a false theory (although I have indicated that there is more is to be considered than the falsity of scientific representations). But my account permits the formulation of adequacy conditionsbased among other things on social values — even without the condition's violation having any 
tangible social consequences. After all, adequacy conditions stem from a theory's purpose or what the theory is intended to represent; and in case of a theory being meant to offer a scientific explanation (the context in which I introduced the idea of adequacy conditions), such an adequacy condition obtains regardless of whether putting forward a non-explanatory scientific account would have any social consequences. In the case of a primatological theory, in addition to other considerations (e.g., capturing causal features impacting primate sociality), in our current societal context, considerations about gender equity likewise inform the adequacy condition of including the social role of female primates (regardless of consequences on humans). Social values are in this scientific case crucial, because not only do they contribute to specifying what a complete theory has to include, but they are needed to determine that omitting some female contributions counts as a particularly egregious kind of incompleteness. ${ }^{18}$ In summary, if an account of primate sociality or human origins is deemed to be inadequate for 'scientific' reasons, this is to a relevant extent due to the fact that a similar account would be unacceptable when used in accounts of extant humans, for social reasons.

A social value need not have the same implication for what the adequacy conditions are in any context; rather, my claim is that 'gender equity' has this impact in our current social and scientific context. The actual conditions of adequacy of a primatological theory are more specific than what I mentioned above, and making them explicit would require fleshing them out in detail. Indeed, in addition to values, empirical background knowledge is needed to arrive at adequacy conditions. For instance, in Section 4 I mentioned how Lloyd (1993) as a feminist philosopher objects to studies of female primate sexuality that investigate only sex with males (so as to ignore widespread female-female sexual interactions). ${ }^{19}$ A potential objection to Lloyd is that given the studies' aim of arriving at evolutionary explanations, only sexual behaviour increasing reproductive fitness matters. However, recent theoretical work by Joan Roughgarden 
(2009) shows how various non-standard gender behaviours found in the animal kingdom contribute by means of an ecological layer of complex social interactions to the individual's fitness as the ultimate evolutionary currency. Thus, novel empirical work can be used to show that the equating of female sexuality with reproductive sex is inadequate even for the aim of an evolutionary theory. A consequence of this influence of empirical beliefs on adequacy conditions is that a change in empirical assumptions may well lead to a revision in adequacy conditions used, so that a theory once endorsed can no longer be deemed to be adequate.

Other philosophers may acknowledge the relevance of social values, while trying to argue that my case does not demonstrate a stronger role for values in the context of theory acceptance, given that the social considerations are relevant to the choice of research questions and investigative methodologies. For instance, rather than 'investigating primate social life' the research question be more specifically 'investigating the role of males and females in primate social life' and observational methodologies be mindful of androcentric bias. However, from my perspective such social values matter to research problem and methodology choice because the values originate from the intended theory's conditions of adequacy. In Section 3 I already argued that when it comes to the impact of values, different steps of research cannot be segregated. There the focus was on how a value underlying research question choice can sometimes be seen to be problematic only once its effect on other research steps, including theory acceptance, are considered. Now my point is that value considerations in the steps of research question and methodology choice are grounded by the theory's scientific purpose and the theory's conditions of adequacy, and in this sense the context of theory acceptance. Thereby the notions of a theory's purpose and its adequacy conditions, which my framework invokes, have an impact across various aspects of research. In our primatology case, gathering a diversity of evidence so as to be mindful of gender variation and androcentric bias is indeed a desideratum for observational 
methodology, but the underlying values stem from the theory’s purpose. In any case, even if the social values are also operative in the early steps of research, the conditions of adequacy-based in part on these values_-must always be met in theory acceptance.

My account also shows why social values make a positive contribution, rather than it being sufficient to remove problematic social values, such as androcentrism (see also Goldenberg 2015; Kourany 2010, ch. 3). Conditions of adequacy are scientific standards that have to be set up in the first place; and in the case of the evolutionary origin of novelty epistemic values are needed to defend what qualifies as an adequate explanation in this context. In the case of archaeology and primatology, in addition to epistemic values and empirical considerations, feminist values fruitfully contribute to delineating what counts as a complete account of human evolution and the social behaviour of non-human primates.

Helen Longino (1996) has prominently scrutinized the dichotomy between epistemic and non-epistemic values (see also Longino 1995). On her account, in a situation where established biological theories actually have a sexist bias, using the epistemic value of consistency with other theories will work against the acceptance of new, non-sexist accounts, so that in this context this epistemic value also has a social valence. Conversely, values that are social or at least were proposed by feminist discussions of science, e.g., 'novelty' (significantly differing from current theories), 'ontological heterogeneity,' and 'mutuality of interaction,' can in certain contexts further the endorsement of theories that are empirically more adequate. I likewise do not endorse a dichotomy between epistemic and non-epistemic values, as on my account epistemic values, social values, and other values have the same role of (jointly) determining a theory's conditions of adequacy. The contributions of epistemic and social considerations may also be hard to disentangle, for example, covering the role of females in human evolution is in part an epistemic consideration about causal completeness and in part a feminist concern about capturing 
the social significance of women. ${ }^{20}$ Rather than merely calling for diversity of evidence and investigative methods, Longino rightly views feminist values such as 'ontological heterogeneity' as applying to theories — just like the epistemic values of 'simplicity' and 'consistency with other theories' are properties of theories. Yet my account offers a clearer articulation of the impact of values, given that I distinguish between values and conditions of adequacy, where only the latter have to be met by a theory. Values are often quite generic and domain-general, as are the epistemic values of simplicity and consistency with background knowledge, and the social values of gender equity and non-androcentrism. In contrast, the conditions of adequacy that the values determine (in combination with empirical considerations relevant to the scientific domain) are specific standards that a particular theory has to meet.

Some may object that given that different values may legitimately be brought to bear on a theory, there are cases where my account has the implication that the theory is adequate (relative to one set of values) but at the same time inadequate (relative to other values). Note that something similar already obtains in the case of the widely accepted inductive risk accounts, given that a theory may meet one evidential threshold (that stems from only certain practical consequences of erroneously accepting the theory being deemed to be socially problematic) but not another evidential threshold (stemming from a different ethical judgement about the various consequences of acting on a false theory). But my response to the objection is bolder, in that it would be misguided to conceptualize the issue in terms of theories (isolated from any scientific aims and standards) being accepted given the evidential basis. From my perspective, a scientific theory is a tool developed by us for certain intellectual and practical purposes, so that a scientific account has always to be viewed together with the purpose for which it is used. Scientists recognize that models are not all-purpose tools and that different models are required for different epistemic purposes (where some epistemic purposes can even make reality-distorting 
idealizations legitimate). The same holds when the purpose includes social considerations; and there is nothing wrong about a particular theory being adequate for one human purpose but not being adequate for another purpose. My perspective involves a broad construal of theory 'acceptance,' which in line with a good deal of scientific practice is not just the passive belief in individual propositions, but the active scientific development and use of theories (for a certain purpose). ${ }^{21}$ In addition to using a scientific model for some aim specific of a research group, this includes the communication of an overall scientific account to the public — which is by no means an insignificant aspect of science, as scientists' push for being able to speak about their findings without government censorship in the case of Canada's 'death of evidence' issue reminds us.

These considerations show that my account of the role of social values cannot be captured by a framework that exclusively conceptualizes theory acceptance in terms of making inferences from evidence. The broader philosophical framework that is needed for any discussion of values in science (though it can already be found in other philosophical contexts) includes that an important aspect of scientists' acceptance and use of theories are conditions of adequacy, which are concrete, domain-specific standards of what it means for a particular scientific theory to be significant, explanatory, unbiased, complete, or practically applicable. Such standards are based on the epistemic, social and/or environmental purpose for which a scientific theory has been developed and is being used. While such purposes are also germane to the issue of choosing research questions and methodologies for developing scientific accounts, they cannot be neglected in context of theory acceptance. In fact, the purpose for which a theory is to be used and the underlying values have an overarching impact on various aspects of research. 


\section{Conclusion: politicized science or socially responsible science?}

While inductive risk arguments for social values (and likewise underdetermination arguments) operate with an inference-from-evidence framework, I have argued that a broader philosophical framework is needed, which recognizes that scientific theories are developed for certain intellectual or practical purposes and are used to serve human interests. Such a purpose — and the associated epistemic, social, and other values - yield specific conditions of adequacy that a theory has to meet, in addition to merely confirming to an evidential basis. Traditional inductive risk accounts provide a compelling argument for social values being relevant even in the context of theory acceptance. However, an implication of this approach is that the role of values declines whenever evidence accumulates. My account yields not only an additional, but a stronger role for social and other non-epistemic values, because it maintains that a theory's conditions of adequacy are in part determined by such values, and conditions of adequacy always have to be met and thus their role does not decline.

Although the 'death of evidence' issue in Canada is prompted by interference in science from the outside, I indicated that Canadian scientists' response is likewise motivated by political values, including concern for the environment and public health (Section 1). Especially in this latter context, my philosophical framework, which endorses that social and environmental values underlie a scientific theory's purpose (affecting even theory acceptance), may raise the specter of politicized science. Indeed, whereas Heather Douglas’s inductive risk account has been developed to provide a safeguard against politicized science, where the priority of evidence over social values is encapsulated by the idea that the impact of values decreases upon the accumulation of evidence, I reject this latter idea. However, my framework may not permit illicitly politicized science any more than other philosophical accounts, given that I have questioned the success of efforts to erect a clear boundary against politicized science, including 
Douglas's distinction between direct and indirect roles for values (Section 2), and any segregation of different steps of research that restricts the use of values to some particular steps (Section 3).

Moreover, in contrast to clearly problematic instances of politicized science, my account likewise does not permit scientists to distort evidence or to ignore relevant evidence, and a scientific theory has to reflect reality. For instance, the adequacy condition that an account of human evolution include the contribution of women does not mean that one may prefer a fictional account over a veridical account because the former would be less sexist. Instead, historical contributions of women are to be included to the extent to which there is evidence for them, and the kind of contributions actually made are to be captured no matter how similar or dissimilar they are to the contributions of men. ${ }^{22}$ I do not endorse politicized science in that evidence matters to my account of theory acceptance. Still, conforming to evidence is not the only consideration in theory acceptance. For amongst the various representations of some aspects of reality, scientists choose one that suits their particular aims and standards, which often are certain explanatory aims and standards of explanatory adequacy, but can also include social and environmental aims that call for the theory to include relevant features of reality. Scientific models and theories are tools for us that also answer to our intellectual and practical purposes. Given this, just like 'a theory is to be accepted solely because it aligns with the evidential basis' in contrast to 'a theory can be accepted solely because it aligns with one’s scientific or social agenda' is a false dichotomy, I reject the opposition that Douglas views between aiming at understanding about the world and aiming at understanding that suits one's interests:

the purpose of pursuing empirical knowledge ... is to gain knowledge about the world, not to gain an understanding that suits one’s preference. (Douglas 2009, 122) 
In his discussion prompted by the 'death of evidence' issue in Canada, Stathis Psillos (2015) grants a role for social values in science, but notes that the primacy of evidence and the objectivity of science can only be ensured if 'the right kind of values' are used. I agree with this, in fact, within my framework that invokes the notion of a theory's purpose, scientists developing and using a theory for some purpose neither means that this purpose cannot be questioned, nor that the values underlying a scientist's particular choice can be illegitimate. But the use of particular values, including social values, can be justified, where—as Maya Goldenberg (2015) argues—empirical inquiry contributes to the rational evaluation of values. ${ }^{23}$ Overall, my approach is in line with what Janet Kourany (2010) calls the ideal of socially responsible science, which, while committed to epistemically sounds science, considers what the proper social aims are and conducts research so as to further them.

To be sure, my proposal endorses a distinctive role of values, where social and other nonepistemic values impact a theory's conditions of adequacy. While some philosophers may worry that adequacy conditions resulting from an interaction of different types of values (epistemic and social alike) could not be laid out at all, I respond that this is not a problem created only with the addition of non-epistemic values, and that scientists already tackle it as a scientific issue. In the case of evolutionary developmental biology, I pointed out that there are ongoing scientific debates about epistemic standards for what counts as an adequate framework for explaining the evolutionary origin of novelty (Section 5). In the context of human evolution and primate social organization, social considerations about androcentrism have played a role in how the scientists involved have criticized past accounts and attempted to develop more adequate theories. Given that conditions of adequacy and assumptions about the shape of a proper scientific framework are often implicit, it is in fact important that scientists attempt to make such standards and the underlying aims explicit, so that they can reflect on and defend them. And for the purpose of 
scrutiny from outside of science, it is minimally necessary that scientists are transparent about the values they endorse and how they use them. Sure enough, this alone does not yield a social mechanism for the values of the stakeholders affected by the formation and application of particular scientific knowledge having an influence on the scientist's values. But how this can be achieved and the related question (also addressed by Goldenberg 2015 and Psillos 2015) of whose values matter-the scientists', the affected stakeholders', or the societal majority's—is to be discussed as part of an open dialogue that goes beyond a philosopher's treatise.

\section{Acknowledgements}

I am indebted to two anonymous referees for their suggestions on how to improve the manuscript. Some parts of this paper have been presented at the 24-26 May 2014 meeting of the Canadian Society for the History and Philosophy of Science, at the 16 September 2014 lunchtime talk of the Center for Philosophy of Science of the University of Pittsburgh, at the 6-9 November 2014 meeting of the Philosophy of Science Association, at the 5 February colloquium of the Department of Philosophy of the University of Alberta, and at the 30 April 2015 current projects seminar of the Department of Philosophy of the University of Sydney. I thank these audiences for their contributions to the development of my paper, with special thanks to Kathryn Tabb.

\section{Notes on contributor}

Ingo Brigandt is Associate Professor of Philosophy and Canada Research Chair in Philosophy of Biology at the University of Alberta. He has discussed the topics of concepts and conceptual change, reduction and integration, explanation, natural kinds, naturalism, and the nature of science, particularly in the contexts of evolutionary developmental biology, molecular biology, and systems biology. A theme underlying his philosophical works has been to articulate values held by scientists, including explanatory and other investigative aims as well as methodological and explanatory standards, and to investigate how such values guide scientific practice. 


\section{Notes}

${ }^{1}$ Ontario's provincial government and a non-profit organization funded by the Manitoba government have saved the freshwater research station; and in response to protests, the federal government has recently resumed funding for the polar research station.

${ }^{2}$ At its 31 May 2015 annual general meeting, the Canadian Society for the History and Philosophy of Science passed the following motion: 'The Canadian Society for the History and Philosophy of Science endorses the principle of the federal scientists' freedom to communicate, and reaffirms the centrality of the ability of scientists to communicate for the advancement of science.'

${ }^{3}$ Katie Gibbs, an organizer of the 'death of evidence' rally stated 'that these cuts are not just part of fighting the deficit, that there is ... the preferential cutting of programs that may produce results not in line with the Conservative agenda ... But we feel that most Canadians regardless of their values or beliefs think that policies should be made based on evidence and based on facts' (Davison 2012).

${ }^{4}$ My focus is on the intellectual issue of how social values may impact scientific practice and the evaluation of scientific results and theories. A more institutional issue is whether science ought to be autonomous from society and political bodies, which has been critically discussed by Lacey (1999).

${ }^{5}$ Institutional bases of socially relevant philosophy of science are the Association for Feminist Epistemologies, Methodologies, Metaphysics, and Science Studies (first conference in 2004, http://femmss.org), the Joint Caucus of Socially Engaged Philosophers and Historians of Science (since 2012, http://jointcaucus.philsci.org), and the Consortium for Socially Relevant Philosophy of/in Science and Engineering (first conference in 2014, http://srpoise.org).

${ }^{6}$ Longino (1990) uses the labels constitutive values and contextual values, though without viewing the distinction as significant. I comment in Section 5 on the distinction between epistemic and social values.

${ }^{7}$ Though also speaking of 'requiring more evidence' (97), Douglas (2009) typically uses the equivalent formulation in terms of reducing uncertainty (or reducing the possibility of error).

${ }^{8}$ In a similar fashion, Lacey (1999) acknowledges that '[social] values may influence our sense of what sufficiently demanding standards [for theory acceptance] are' (72). But he argues that there is one respect in which science is value-free, in that once the standards are set, a theory is accepted solely based on whether it 'manifests the cognitive [i.e., epistemic] values highly according to the most rigorous available standards’ (224; see also 72).

9 'so-called "epistemic values" are less like values and more like criteria that all theories must succeed in meeting.' (Douglas 2009, 94) 
10 'The indirect role, in contrast, can completely saturate science, without threat to the integrity of science' (Douglas 2009, 96). Elliott (2011a) critically analyzes the idea of direct vs. indirect roles, and concludes that while the distinction may be articulated as a normative ideal, it has limited use for practically regulating how values influence science.

${ }^{11}$ Douglas (2009) does not explain this either in the concrete scientific case she addresses to illustrate her framework (108-112). From the 1940s on the synthetic estrogen diethylstilbestrol was given to pregnant women to prevent miscarriages - based on the idea that such 'female' problems were due to a lack of enough female hormones. Despite evidence that diethylstilbestrol did not reduce the number of miscarriages and even had harmful effects, it was not withdrawn from the market until the 1970s. Douglas argues that the use of both social values (stability in fixed gender roles) and cognitive values (simplicity, scope, explanatory power, and consistency with other theories of the day) favoured the misguided acceptance of the effectiveness of diethylstilbestrol. However, while claiming that the bad science resulted because these cognitive and other values played a direct role, Douglas never indicates what the indirect role for simplicity and the other cognitive values would be in this concrete situation (and how this indirect role would have made for better science in this instance). In a more recent paper, Douglas (2013b) discusses cognitive values, including simplicity, but does not mention the distinction between direct and indirect roles.

${ }^{12}$ Eichler's (1988, ch. 7) classical guide on non-sexist methods in social science research addresses problems with concepts and the formation of appropriate ones in detail. Anderson (1995, 45-49) discusses problematic economic definitions of 'employment rate’ (which when excluding part-time work can fail to address the social situation of women) and psychological categorizations of personality characteristics (which may assume that certain 'masculine' behaviours and preferences are thereby not 'feminine').

${ }^{13}$ Furthermore, even if the account showed that a direct role is illicit, Douglas does not explain what the alternative, licit use of a social value in an indirect role is in the context of research problem choice, and, as I pointed out in Section 2, it is obscure what it could be.

${ }^{14}$ Brown (2013) phrases this as inductive risk accounts endorsing a 'lexical priority of evidence over values' (which may overstate the issue), and notes that such a priority assumption also holds for underdetermination arguments for values. Like me, Brown assumes that values should play a deeper role than on these traditional accounts (though he does not articulate what this role would be).

${ }^{15}$ Equating the concept of 'female sexuality' with 'female reproductive behaviour' is the use of a category. Even if it was motivated by an evolutionary research question (aiming to study reproductive success), this category affects all steps of research, as pointed out in Section 3. 
${ }^{16}$ Sometimes inductive risk accounts are in fact presented as if it was solely about the amount of evidence, rather than also about the kind of evidence needed: 'deciding how much evidence is enough to support making an empirical claim,' 'requiring more evidence when such consequences are dire,' 'more evidence arises that reduces uncertainty in the choice' (Douglas 2009, 80, 97 \& 107); 'deciding how much evidence to demand when accepting a scientific hypothesis,' 'how much evidence is required for theory acceptance' (Elliott 2011b, 66 \& 68; in addition to inductive risk, he endorses other ways in which values matter). There are also broader views of the evidential basis: Steel $(2010,2013)$ typically uses the phrase 'standards of evidence,' which could be seen as including the kind of evidence needed for theory acceptance. Moreover, Douglas states that in addition to theory acceptance, 'significant inductive risk is present at ... [the] choice of methodology, [and the] gathering and characterization of the data' (2000, 565; see also 2009, 103). It is less clear, though, how a methodology and especially a practice of gathering data could be an empirical claim with a truth-value, so that her inductive risk approach in terms of the uncertainty of empirical claims and the consequences of endorsing a false empirical claim could gain traction.

But it actually does not matter whether the way in which values guide the proper gathering of evidence is seen as part of inductive risk or as a separate role for values (orthogonal to inductive risk as pertaining to the evidence-theory relation), given that beyond the focus on the evidential basis my framework to be developed will in any case be broader by pointing to the intended theory and the aims of developing a particular theory. In this fashion my approach will go beyond many accounts of the role of values, not just inductive risk accounts.

${ }^{17}$ Longino (2013) discusses how different approaches (and fields) investigating human aggression and sexuality partition the causal space differently, which also results in different implicit assumptions about what an adequate explanation looks like. Likwornik (2015) also highlights the impact of opaque (implicit) values on the scientific process.

${ }^{18}$ One cannot exclude that there can be different justifications for the same set of adequacy conditions. Even if the adequacy conditions of a primatological theory could be articulated involving social values but also based on purely epistemic considerations, my position would still be that deeming social values to be irrelevant given the availability of a purely epistemic justification is an illicit preference for one way of justifying conditions of adequacy. My own approach is to view both epistemic and social values as making a fruitful contribution and to employ them in a joint fashion when articulating adequacy conditions.

19 'When I pointed out that the vast majority of female stumptail orgasms occurred during sex among the females alone, [the primatologist studying only female orgasms occurring in male-female sex] 
replied that yes, he knew that, but he was only interested in the important orgasms.' (Lloyd 1993, 142)

${ }^{20}$ Likwornik (2015) discusses other aspects of the entwinement of empirical claims and values.

${ }^{21}$ The aims underlying the formation and use of scientific representations, in particular quantitative models, have been addressed by philosophical accounts of model-based science (Potochnik 2012; see also Brigandt 2013; Giere 2006; van Fraassen 2008). Among the aims of a model user, Elliott and McKaughan (2014) include non-epistemic values, e.g., concern for human health and the environment. They argue that non-epistemic values can override such epistemic considerations as fit with reality. In her critical discussion of underdetermination arguments for social values, Intemann (2005) likewise recognizes that a different 'way that contextual [i.e., non-epistemic] values might legitimately play a role in theory justification would be if such values were somehow inextricably connected to the aims of (at least some) scientific research contexts' (1010). (She views nonepistemic values as applying and adjudicating between epistemic values, whereas my account views epistemic and other values on the same level, and introduces a theory's conditions of adequacy as distinct from values.)

${ }^{22}$ Section 3 mentioned Kourany's (2010) example of a study on domestic violence in black communities, which faced the dual challenge of exhibiting problems encountered specifically by black women without perpetuating the racist stereotype that black men are inherently more violent. Similar to me, Kourany argues that research that attempts to avoid racism is still committed to evidence. All such a research program requires 'is that dissimilarities in domestic violence within the black and white communities be explained, as far as empirically possible, in terms of social differences such as racism and poverty. The program does not guarantee that any of these explanations will be successful' (72).

${ }^{23}$ Psillos (2015) views those social values as legitimate for use in science that can be universalised, making reference to feminist standpoint epistemologies and Marxist theories of social emancipation, e.g., the idea that the interests of the proletariat are 'universal' interests in the sense that everyone would benefit from them. Viewing this as too restrictive given that not all relevant values are universalisable, Goldenberg (2015) adopts the alternative approach of an empirical justification of (legitimate) values, in line with feminist empiricism.

\section{References}

Anderson, Elizabeth. 1995. "Knowledge, Human Interests, and Objectivity in Feminist Epistemology." Philosophical Topics 23 (2): 27-58. 
Anderson, Elizabeth. 2004. "Uses of Value Judgments in Science: A General Argument, with Lessons from a Case Study of Feminist Research on Divorce." Hypatia 19 (1): 1-24. Barker, Gillian, and Philip Kitcher. 2013. Philosophy of Science: A New Introduction. Oxford: Oxford University Press.

Brigandt, Ingo. 2013. "Explanation in Biology: Reduction, Pluralism, and Explanatory Aims." Science \& Education 22 (1): 69-91.

Brigandt, Ingo, and Alan C. Love. 2012. "Conceptualizing Evolutionary Novelty: Moving Beyond Definitional Debates." Journal of Experimental Zoology Part B: Molecular and Developmental Evolution 318 (6): 417-427.

Brown, Matthew J. 2013. "Values in Science Beyond Underdetermination and Inductive Risk." Philosophy of Science 80 (5): 829-839.

Campbell, Richmond. 1994. "The Virtues of Feminist Empiricism." Hypatia 9 (1): 90-115.

Campbell, Richmond. 1998. Illusions of Paradox: A Feminist Epistemology Naturalized. Lanham: Rowman and Littlefield.

CBC News. 2012. "Muzzling of Federal Scientists Targeted by Campaign." CBC News, February 17. http://www.cbc.ca/news/technology/muzzling-of-federal-scientists-targeted-bycampaign-1.1153318.

CBC News. 2015. "Steve Campana, Canadian Biologist, 'Disgusted' with Government Muzzling." CBC News, May 19. www.cbc.ca/news/canada/nova-scotia/steve-campanacanadian-biologist-disgusted-with-government-muzzling-1.3078587.

Conkey, Margaret W., and Joan M. Gero. 1997. "Programme to Practice: Gender and Feminism in Archaeology." Annual Review of Anthropology 26: 411-437.

Conkey, Margaret W., and Janet D. Spector. 1984. "Archaeology and the Study of Gender." Advances in Archaeological Method and Theory 7: 1-38.

Craver, Carl F. 2007. Explaining the Brain: Mechanisms and the Mosaic Unity of Neuroscience. Oxford: Oxford University Press.

Davison, Janet. 2012. "Scientists Rally on Parliament Hill to Mourn 'Death of Evidence'." CBC News, July 9. http://www.cbc.ca/news/technology/scientists-rally-on-parliament-hill-tomourn-death-of-evidence-1.1237215.

de Melo-Martín, Inmaculada, and Kristen Intemann. 2011. "Feminist Resources for Biomedical Research: Lessons from the Hpv Vaccines." Hypatia 26 (1): 79-101. 
Dorato, Mauro. 2004. "Epistemic and Nonepistemic Values in Science." In Science, Values, and Objectivity, edited by Peter Machamer and Gereon Wolters, 52-77. Pittsburgh: University of Pittsburgh Press.

Douglas, Heather E. 2000. "Inductive Risk and Values in Science." Philosophy of Science 67 (4): 559-579.

Douglas, Heather E. 2009. Science, Policy, and the Value-Free Ideal. Pittsburgh: University of Pittsburgh Press.

Douglas, Heather E. 2013a. "Opinion: Canadian Science under Attack." The Scientist, April 2. http://www.the-scientist.com/?articles.view/articleNo/34958/title/Opinion--CanadianScience-Under-Attack/.

Douglas, Heather E. 2013b. "The Value of Cognitive Values." Philosophy of Science 80 (5): 796-806.

Eichler, Margrit. 1988. Nonsexist Research Methods: A Practical Guide. Boston: Allen \& Unwin.

Elliott, Kevin C. 2011a. "Direct and Indirect Roles for Values in Science." Philosophy of Science 78 (2): 303-324.

Elliott, Kevin C. 2011b. Is a Little Pollution Good for You? Incorporating Societal Values in Environmental Research. Oxford: Oxford University Press.

Elliott, Kevin C., and Daniel J. McKaughan. 2014. "Nonepistemic Values and the Multiple Goals of Science." Philosophy of Science 81 (1): 1-21.

Fedigan, Linda Marie. 1997. "Is Primatology a Feminist Science?" In Women in Human Evolution, edited by Lori D. Hager, 56-75. London: Routledge.

Galloway, Gloria. 2013a. "Scientists Feel Muzzled by Conservative Government, Union Says." Globe and Mail, October 21. http://www.theglobeandmail.com/news/politics/scientistsfeel-muzzled-by-conservative-government-union-says/article14960779/.

Galloway, Gloria. 2013b. "Tories Take Heat in House on Science Policy, Closing Research Station." Globe and Mail, March 20. http://www.theglobeandmail.com/news/politics/tories-take-heat-in-house-on-sciencepolicy-closing-research-station/article10042858/.

Gatehouse, Jonathon. 2013. "When Science Goes Silent: With the Muzzling of Scientists, Harper's Obsession with Controlling the Message Verges on the Orwellian." Maclean's Magazine, May 3. http://www.macleans.ca/news/canada/when-science-goes-silent/. 
Giere, Ronald N. 2006. Scientific Perspectivism. Chicago: University of Chicago Press.

Globe and Mail. 2013. "Closing of Research Stations Belies Ottawa's Claim That It Is Protecting the Environment." Globe and Mail, March 19. http://www.theglobeandmail.com/globedebate/editorials/closing-of-research-stations-belies-ottawas-claim-that-it-is-protectingthe-environment/article9940694/.

Globe and Mail. 2014. "Ottawa's Silencing of Scientists Should End." Globe and Mail, October 26. http://www.theglobeandmail.com/globe-debate/editorials/ottawas-silencing-ofscientists-should-end/article21293769/.

Goldenberg, Maya J. 2015. "Whose Social Values? Evaluating Canada's "Death of Evidence" Controversy." Canadian Journal of Philosophy, this issue.

Goldenberg, Suzanne. 2013a. "Artist Finds Inspiration in Canadian Government's Attempt to Silence Her." The Guardian, May 17. http://www.theguardian.com/environment/2013/may/17/artist-inspiration-canada-silenceclimate.

Goldenberg, Suzanne. 2013b. "Canadian Oil Minister Joe Oliver Condemns Climatologist James Hansen." The Guardian, April 24. http://www.theguardian.com/environment/2013/apr/24/canada-joe-oliver-attack-jameshansen.

Haack, Susan. 1993. Evidence and Inquiry: Towards Reconstruction in Epistemology. Oxford: Blackwell.

Haack, Susan. 1996. "Science as Social? - Yes and No." In Feminism, Science, and the Philosophy of Science, edited by Lynn Hankinson Nelson and Jack Nelson, 79-93. Dordrecht: Kluwer.

Hanen, Marsha, and Jane Kelley. 1992. "Gender and Archaeological Knowledge." In Metaarchaeology: Reflections by Archaeologists and Philosophers, edited by Lester Embree, 195-225. Springer Netherlands.

Harris, Michael. 2014. Party of One: Stephen Harper and Canada's Radical Makeover. Toronto: Penguin Group Canada.

Hempel, Carl Gustav. 1965. "Science and Human Values." In Aspects of Scientific Explanation and Other Essays in the Philosophy of Science. New York: Free Press.

Hoag, Hannah. 2008. "Canada Abolishes Its National Science Adviser." Nature 451 (January 31): 505. 
Hrdy, Sarah Blaffer. 1981. The Woman That Never Evolved. Cambridge, MA: Harvard University Press.

Hrdy, Sarah Blaffer. 1986. "Empathy, Polyandry, and the Myth of the Coy Female." In Feminist Approaches to Science, edited by Ruth Bleier, 119-146. New York: Pergamon Press.

Intemann, Kristen. 2001. "Science and Values: Are Value Judgments Always Irrelevant to the Justification of Scientific Claims?" Philosophy of Science 68 (3): S506-S518.

Intemann, Kristen. 2005. "Feminism, Underdetermination, and Values in Science." Philosophy of Science 72 (5): 1001-1012.

Kincaid, Harold, John Dupré, and Alison Wylie, eds. 2007. Value-Free Science? Ideals and Illusions. Oxford: Oxford University Press.

Kitcher, Philip. 1985. Vaulting Ambition: Sociobiology and the Quest for Human Nature. Cambridge, MA: MIT Press.

Kitcher, Philip. 2001. Science, Truth, and Democracy. Oxford: Oxford University Press.

Klinkenborg, Verlyn. 2013. "Silencing Scientists." New York Times, September 21. http://www.nytimes.com/2013/09/22/opinion/sunday/silencing-scientists.html.

Kourany, Janet A. 2010. Philosophy of Science after Feminism. Oxford: Oxford University Press.

Lacey, Hugh. 1999. Is Science Value Free? Values and Scientific Understanding. London: Routledge.

Lacey, Hugh. 2004. "Is There a Significant Distinction between Cognitive and Social Values?" In Science, Values, and Objectivity, edited by Peter Machamer and Gereon Wolters, 2451. Pittsburgh: University of Pittsburgh Press.

Laudan, Larry. 1984. Science and Values: An Essay on the Aims of Science and Their Role in Scientific Debate. Berkeley: University of California Press.

Laudan, Larry. 2004. "The Epistemic, the Cognitive, and the Social." In Science, Values, and Objectivity, edited by Peter Machamer and Gereon Wolters, 14-23. Pittsburgh: University of Pittsburgh Press.

Likwornik, Helena. 2015. "Who's Afraid of the Big Bad Wolf? The Interweaving of Values and Science." Canadian Journal of Philosophy, this issue.

Linnitt, Carol. 2013. "Harper's Attack on Science: No Science, No Evidence, No Truth, No Democracy." Academic Matters, May 30. 
http://www.academicmatters.ca/2013/05/harpers-attack-on-science-no-science-noevidence-no-truth-no-democracy/.

Lloyd, Elisabeth A. 1993. "Pre-Theoretical Assumptions in Evolutionary Explanations of Female Sexuality." Philosophical Studies 69 (2/3): 139-153.

Lloyd, Elisabeth A. 2005. The Case of the Female Orgasm: Bias in the Science of Evolution. Cambridge, MA: Harvard University Press.

Longino, Helen E. 1990. Science as Social Knowledge: Values and Objectivity in Scientific Inquiry. Princeton: Princeton University Press.

Longino, Helen E. 1995. "Gender, Politics, and the Theoretical Virtues." Synthese 104 (3): 383397.

Longino, Helen E. 1996. "Cognitive and Non-Cognitive Values in Science: Rethinking the Dichotomy." In Feminism, Science and the Philosophy of Science, edited by Lynn Hankinson Nelson and Jack Nelson, 39-58. Dordrecht: Kluwer.

Longino, Helen E. 2002. The Fate of Knowledge. Princeton: Princeton University Press.

Longino, Helen E. 2013. Studying Human Behavior: How Scientists Investigate Aggression and Sexuality. Chicago: University of Chicago Press.

Love, Alan C. 2008. "Explaining Evolutionary Innovations and Novelties: Criteria of Explanatory Adequacy and Epistemological Prerequisites." Philosophy of Science 75 (5): 874-886.

Love, Alan C. 2013a. "Interdisciplinary Lessons for the Teaching of Biology from the Practice of Evo-Devo." Science \& Education 22 (2): 255-278.

Love, Alan C. 2013b. "Teaching Evolutionary Developmental Biology: Concepts, Problems, and Controversy." In The Philosophy of Biology: A Companion for Educators, edited by Kostas Kampourakis, 323-341. Dordrecht: Springer.

Love, Alan C. 2013c. "Theory Is as Theory Does: Scientific Practice and Theory Structure in Biology." Biological Theory 7 (4): 325-337.

Love, Alan C., and Gary L. Lugar. 2013. "Dimensions of Integration in Interdisciplinary Explanations of the Origin of Evolutionary Novelty." Studies in History and Philosophy of Biological and Biomedical Sciences 44 (4A): 537-550.

Lundh, Andreas, Sergio Sismondo, Joel Lexchin, Octavian A. Busuioc, and Lisa Bero. 2012. "Industry Sponsorship and Research Outcome." The Cochrane Library 12: MR000033. 
Machamer, Peter, and Gereon Wolters, eds. 2004. Science, Values, and Objectivity. Pittsburgh: University of Pittsburgh Press.

McMullin, Ernan. 1983. "Values in Science." In PSA: Proceedings of the 1982 Biennial Meeting of the Philosophy of Science Association (Volume Two, Symposia and Invited Papers), edited by Peter D. Asquith and Thomas Nickles, 3-28. East Lansing: Philosophy of Science Association.

Mooney, Chris. 2005. The Republican War on Science. New York: Basic Books.

Nature. 2008. "Science in Retreat: Canada Has Been Scientifically Healthy. Not So Its Government." Nature 451 (February 21): 866-866.

Nature. 2012. "Death of Evidence: Changes to Canadian Science Raise Questions That the Government Must Answer." Nature 487 (July 19): 271-272.

Nature. 2013. "Frozen Out: Canada's Government Should Free Its Scientists to Speak to the Press, as Its Us Counterpart Has." Nature 483 (March 1): 6.

O'Hara, Kathryn. 2010. "Canada Must Free Scientists to Talk to Journalists." Nature 467 (September 29): 501.

Ottawa Citizen. 2008. "Environment Canada 'Muzzles' Scientists' Dealings with Media." Ottawa Citizen, February 1. http://www.canada.com/ottawacitizen/news/story.html?id=55e49c18-cb8d-45dd-a2d322dc0f053f18.

Pedwell, Terry. 2012. "Scientists Take Aim at Harper Cuts with 'Death of Evidence’ Protest on Parliament Hill." Globe and Mail, July 10. http://www.theglobeandmail.com/news/politics/scientists-take-aim-at-harper-cuts-withdeath-of-evidence-protest-on-parliament-hill/article4403233/.

Plaisance, Kathryn S., and Carla Fehr, eds. 2010. Making Philosophy of Science More Socially Relevant. Special issue of Synthese (Volume 177, Issue 3).

Potochnik, Angela. 2012. "Feminist Implications of Model-Based Science." Studies in History and Philosophy of Science 43 (2): 383-389.

Psillos, Stathis. 2015. "Evidence: Wanted, Alive or Dead." Canadian Journal of Philosophy, this issue.

Reardon, Sara. 2011. "Canadian Fish Scientist 'Muzzled' by Government." Science Magazine News, July 28. http://news.sciencemag.org/2011/07/canadian-fish-scientist-muzzledgovernment. 
Robert, Jason. 2004. Embryology, Epigenesis, and Evolution: Taking Development Seriously. Cambridge: Cambridge University Press.

Rollmann, Hans. 2014. "Getting Science Wrong, with Dire Consequences: Researchers Warn of the Growing Impact of Political Intervention on Scientific Research in Canada." TheIndependent.ca, April 25. http://theindependent.ca/2014/04/25/getting-sciencewrong-with-dire-consequences.

Rooney, Phyllis. 1992. "On Values in Science: Is the Epistemic/Non-Epistemic Distinction Useful?" In PSA 1992: Proceedings of the 1992 Biennial Meeting of the Philosophy of Science Association, Volume 1, edited by David Hull, Micky Forbes, and Kathleen Okruhlik, 13-22. East Lansing: Philosophy of Science Association.

Rottschaefer, William A. 2003. "Assessing the Role of Non-Epistemic Feminist Values in Scientific Inquiry." Behavior and Philosophy 31: 225-249.

Roughgarden, Joan. 2009. The Genial Gene: Deconstructing Darwinian Selfishness. Berkeley: University of California Press.

Rudner, Richard. 1953. "The Scientist Qua Scientist Makes Value Judgments." Philosophy of Science 20 (1): 1-6.

Saunders, Craig. 2009. "Are Environment Canada Gatekeepers Gagging Their Own Scientists?" This Magazine, July 31. http://this.org/magazine/2009/07/31/environment-canadagagging-researchers/.

Schiebinger, Londa. 1999. Has Feminism Changed Science? Cambridge, MA: Harvard University Press.

Schienke, Erich W., Seth D. Baum, Nancy Tuana, Kenneth J. Davis, and Klaus Keller. 2011. "Intrinsic Ethics Regarding Integrated Assessment Models for Climate Management." Science and Engineering Ethics 17 (3): 503-523.

Semeniuk, Ivan. 2015. "Federal Scientists Push for Protection from Political Interference." Globe and Mail, May 17. http://www.theglobeandmail.com/news/national/federal-scientistspush-for-protection-from-political-interference/article24473222/.

Small, Meredith F., ed. 1984. Female Primates: Studies by Women Primatologists. New York: A. R. Liss.

Smith, Richard. 2005. "Medical Journals Are an Extension of the Marketing Arm of Pharmaceutical Companies." PLoS Medicine 2: e138. 
Steel, Daniel. 2010. "Epistemic Values and the Argument from Inductive Risk." Philosophy of Science 77 (1): 14-34.

Steel, Daniel. 2013. "Acceptance, Values, and Inductive Risk." Philosophy of Science 80 (5): 818-828.

Strum, Shirley C., and Linda Marie Fedigan. 1999. "Theory, Method, Gender and Culture: What Changed Our Views of Primate Society?" In The New Physical Anthropology, edited by Shirley C. Strum, Donald G. Lindburg, and David A. Hamburg, 67-105. Upper Saddle River: Prentice Hall.

Strum, Shirley C., and Linda Marie Fedigan, eds. 2000. Primate Encounters: Models of Science, Gender, and Society. Chicago: University of Chicago Press.

The Canadian Press. 2012. "Prestigious Science Journal Slams Harper Government's Muzzle on Federal Scientists." The Star, March 1. http://www.thestar.com/news/canada/2012/03/01/prestigious_science_journal_slams_har per_governments_muzzle_on_federal_scientists.html.

Turner, Chris. 2013. The War on Science: Muzzled Scientists and Wilful Blindness in Stephen Harper's Canada. Vancouver: Greystone Books.

van Fraassen, Bas. 2008. Scientific Representation: Paradoxes of Perspective. Oxford: Oxford University Press.

West, Carolyn. 2002. "Black Battered Women: New Directions for Research and Black Feminist Theory." In Charting a New Course for Feminist Psychology, edited by Lynn Collins, Michelle Dunlap, and Joan Chrisler, 216-237. Westport: Praeger.

Wylie, Alison, and Lynn Hankinson Nelson. 2007. "Coming to Terms with the Values of Science: Insights from Feminist Science Scholarship." In Value-Free Science? Ideals and Illusions, edited by Harold Kincaid, John Dupré, and Alison Wylie, 58-86. Oxford: Oxford University Press.

Zihlman, Adriene. 1997. "The Paleolithic Glass Ceiling: Women in Human Evolution." In Women in Human Evolution, edited by Lori D. Hager, 91-113. London: Routledge. 